\title{
Airborne particulate matter monitoring in Kenya using calibrated low-cost sensors
}

\author{
Francis D. Pope ${ }^{1}$, Michael Gatari ${ }^{2}$, David Ng'ang'a ${ }^{2}$, Alexander Poynter ${ }^{1}$, and Rhiannon Blake ${ }^{1}$ \\ ${ }^{1}$ School of Geography, Earth and Environmental Sciences, University of Birmingham, \\ B15 2TT Birmingham, UK \\ ${ }^{2}$ Institute of Nuclear Science and Technology, University of Nairobi, Nairobi, Kenya
}

Correspondence: Francis D. Pope (f.pope@bham.ac.uk)

Received: 27 March 2018 - Discussion started: 14 May 2018

Revised: 26 September 2018 - Accepted: 1 October 2018 - Published: 26 October 2018

\begin{abstract}
East African countries face an increasing threat from poor air quality stemming from rapid urbanization, population growth, and a steep rise in fuel use and motorization rates. With few air quality monitoring systems available, this study provides much needed high temporal resolution data to investigate the concentrations of particulate matter (PM) air pollution in Kenya. Calibrated low-cost optical particle counters (OPCs) were deployed in Kenya in three locations: two in the capital Nairobi and one in a rural location in the outskirts of Nanyuki, which is upwind of Nairobi. The two Nairobi sites consist of an urban background site and a roadside site. The instruments were composed of an AlphaSense OPC-N2 ran with a Raspberry Pi low-cost microcomputer, packaged in a weather-proof box. Measurements were conducted over a 2-month period (February-March 2017) with an intensive study period when all measurements were active at all sites lasting 2 weeks. When collocated, the three OPC$\mathrm{N} 2$ instruments demonstrated good inter-instrument precision with a coefficient of variance of $8.8 \pm 2.0 \%$ in the fine particle fraction $\left(\mathrm{PM}_{2.5}\right)$. The low-cost sensors had an absolute PM mass concentration calibration using a collocated gravimetric measurement at the urban background site in Nairobi.

The mean daily $\mathrm{PM}_{1}$ mass concentration measured at the urban roadside, urban background and rural background sites were $23.9,16.1$ and $8.8 \mu \mathrm{g} \mathrm{m}^{-3}$, respectively. The mean daily $\mathrm{PM}_{2.5}$ mass concentration measured at the urban roadside, urban background and rural background sites were 36.6, 24.8 and $13.0 \mu \mathrm{g} \mathrm{m}^{-3}$, respectively. The mean daily $\mathrm{PM}_{10}$ mass concentration measured at the urban roadside, urban background and rural background sites were 93.7,
\end{abstract}

53.0 and $19.5 \mu \mathrm{g} \mathrm{m}^{-3}$, respectively. The urban measurements in Nairobi showed that PM concentrations regularly exceed WHO guidelines in both the $\mathrm{PM}_{10}$ and $\mathrm{PM}_{2.5}$ size ranges. Following a "Lenschow"-type approach we can estimate the urban and roadside increments that are applicable to Nairobi (Lenschow et al., 2001). The median urban increment is $33.1 \mu \mathrm{g} \mathrm{m}^{-3}$ and the median roadside increment is $43.3 \mu \mathrm{g} \mathrm{m}^{-3}$ for $\mathrm{PM}_{2.5}$. For $\mathrm{PM}_{1}$, the median urban increment is $4.7 \mu \mathrm{g} \mathrm{m}^{-3}$ and the median roadside increment is $12.6 \mu \mathrm{g} \mathrm{m}^{-3}$. These increments highlight the importance of both the urban and roadside increments to urban air pollution in Nairobi.

A clear diurnal behaviour in PM mass concentration was observed at both urban sites, which peaks during the morning and evening Nairobi rush hours; this was consistent with the high roadside increment indicating that vehicular traffic is a dominant source of PM in the city, accounting for approximately $48.1 \%, 47.5 \%$ and $57.2 \%$ of the total PM loading in the $\mathrm{PM}_{10}, \mathrm{PM}_{2.5}$ and $\mathrm{PM}_{1}$ size ranges, respectively. Collocated meteorological measurements at the urban sites were collected, allowing for an understanding of the location of major sources of particulate matter at the two sites. The potential problems of using low-cost sensors for PM measurement without gravimetric calibration available at all sites are discussed.

This study shows that calibrated low-cost sensors can be successfully used to measure air pollution in cities like Nairobi. It demonstrates that low-cost sensors could be used to create an affordable and reliable network to monitor air quality in cities. 


\section{Introduction}

Recently, the Lancet Commission on pollution and health estimated that in 2015 , air pollution led to the premature deaths of over 9 million people globally, and contributed to over one in four deaths in severely affected countries (Landrigan et al., 2017). Typically, urban air pollution is higher in lowand middle-income countries (LMICs) compared to further developed countries. Hence, the associated risk of air pollution to health is typically higher in LMICs, with over $92 \%$ of global pollution-related deaths occurring in these countries. Within LMICs, health inequalities in urban areas contribute to an increased exposure to air pollution that expose those that live, work, socialize and commute to highly urbanized areas, which typically have a substantially higher concentration of air pollutants. Despite the extensive links between air pollutants and human health, environmental degradation, and the economy, air pollution is as of yet still under-researched in many LMICs. Due to a lack of long-term air-quality monitoring in many LMICs, the concentrations and sources of air pollution are poorly understood.

Airborne particulate matter (PM) is a major environmental risk factor with well-documented short- and longterm effects on human mortality and morbidity (Thurston et al., 2016). Long-term side effects to air pollution exposure include asthma, chronic obstructive pulmonary disease (COPD), pulmonary fibrosis, cancer, type 2 diabetes, neurodegenerative diseases, obesity and other conditions (Ferranti et al., 2017; Landrigan et al., 2017). People who are already susceptible to underlying respiratory disease, pneumonia, influenza or asthma can see a worsening of their symptoms and illnesses through short-term exposure to air pollution (Wan Mahiyuddin et al., 2013). The size of PM is correlated with their health impacts, with smaller particles typically having more significant health implications (Meng et al., 2013). $\mathrm{PM}_{1}, \mathrm{PM}_{2.5}$ and $\mathrm{PM}_{10}$ are particulate matter with aerodynamic diameters less than $1,2.5$ and $10 \mu \mathrm{m}$, respectively. The World Health Organization (WHO) recommends that $\mathrm{PM}_{2.5}$ and $\mathrm{PM}_{10}$ daily mass concentrations should not exceed 25 and $50 \mathrm{\mu g} \mathrm{m}^{-3}$, respectively; and annual mass concentrations do not exceed 10 and $20 \mu \mathrm{g} \mathrm{m}^{-3}$, respectively (WHO, 2006). At present, the WHO or other regulatory bodies do not provide recommendations of the mass concentrations of $\mathrm{PM}_{1} . \mathrm{PM}_{1}$ can remain suspended in air for much longer than coarser PM, as well as penetrating deeper into the lungs leading to local pulmonary and systematic inflammation (Pateraki et al., 2014). Due to the smaller size, $\mathrm{PM}_{1}$ has a higher surface to mass ratio, containing a harmful amount of potentially toxic anthropogenic constituents which could lead to health impacts such as respiratory disease, heart disease and lung cancer (Trippetta et al., 2016). Many studies still focus on $\mathrm{PM}_{10}$ and $\mathrm{PM}_{2.5}$ even though smaller particulates pose greater health impacts (Tsiouri et al., 2015). Beyond $\mathrm{PM}_{1}$, ultra-fine particles $(<100 \mathrm{~nm})$ are of such a small size that they can be translocated to the central nervous sys- tem via the blood-brain barrier or the olfactory bulb (Chen et al., 2016). There are no air quality regulations for $\mathrm{PM}_{1}$ or ultra-fine particles due to the paucity of data either within environmental science or public health.

Worldwide, road traffic is a dominant source of urban PM accounting for 5\%-80\% of PM mass, with the precise amount being dependent upon several factors including time, location and vehicle fleet, as reviewed by Pant and Harrison (2013). Vehicle-derived PM is directly associated with negative health outcomes (Fan et al., 2006; HEI, 2010). Emissions are due both to both exhaust-pipe emissions and non-exhaust-pipe emissions. Exhaust emissions result from the combustion of fuel, predominantly petrol and diesel, such as oil and other lubricants. Non-exhaust emissions come either from the resuspension of road dust through wind- or vehicle-induced wind shear, or from the wear and tear of vehicle parts including the brakes, tyres and clutch. Resuspension of dust is particularly important on non-paved roads of which there are an abundance in Nairobi. Typically, nonexhaust emissions are in the coarse PM size fraction (PM in the size range $2.5-10 \mu \mathrm{m}$ aerodynamic diameter), whereas exhaust emissions are in the fine PM size fraction $\left(\mathrm{PM}_{2.5}\right)$ (Thorpe et al., 2007; Kam et al., 2012). However, it is noted that the papers which reference vehicle PM size distributions according to the emission of non-exhaust sources have typically been conducted in either the US or European studies and not in Africa, where non-paved road sources represent a much higher fraction of road surface types. The precise size of vehicular-derived PM is dependent on several factors: vehicle fleet characteristics (e.g. weight and size), road type, level of maintenance and meteorological conditions (Beddows et al., 2009; Hays et al., 2011).

In many cities of LMICs, urbanization, population, fuel use and motorization rates are all increasing rapidly and increases in air pollution are associated with these trends (Mitlin and Satterhwaite, 2013; Ochieng et al., 2017). In particular, vehicular traffic is fast on the rise, with associated congestion on the road networks, which can contribute as much as $90 \%$ to air pollution in urban environments (Kinney et al., 2011). Nairobi is the capital city of Kenya and is showing these trends. In particular, the city population has increased dramatically, since 1999 to 2015 it has risen by $83 \%$, and is projected to increase to 7.14 million by 2030 (Rajé et al., 2017). Similarly, motorization rates are increasing; between 2008 and 2012, the number of motor- and auto-cycles in Kenya grew by $368 \%$ with the number of overall registered vehicles increasing by $77 \%$ (Rajé et al., 2017). Considering this extensive increase in the vehicle fleet, limited roadway infrastructure and high congestion within the city, pollution hotspots are created leading to personal exposure levels much higher than that encountered throughout the rest of the city (van Vliet and Kinney, 2007).

To be able to reduce air pollution, it is helpful to be able to measure it, so reduction efforts can be assessed. Many LMICs have insufficient monitoring networks through 
which to measure air quality. In particular, long-term highresolution data are required for such cities which are vulnerable to air pollution. Nairobi is in the vanguard of air pollution measurements for sub-Saharan Africa (SSA) but lacks continuous long-term calibrated measurements of PM and other air pollutants (Petkova et al., 2013). A discussion of the relevant measurements in Nairobi is given in the next section. One of the constraints to making measurements is the high cost of research-grade air quality monitoring equipment with appropriate calibration and certification. Low-cost sensors offer the potential for dramatically reducing equipment costs by orders of magnitude, making the monitoring of air quality more accessible and attainable in LMICs (Lewis et al., 2016; Rai et al., 2017).

In this paper, the use of low-cost sensors for measurement of $\mathrm{PM}_{1}, \mathrm{PM}_{2.5}$ and $\mathrm{PM}_{10}$ in Nairobi is detailed. We have previously assessed the same low-cost sensors in the UK (Crilley et al., 2018). The sensors are calibrated using a standardized gravimetric approach. PM is measured in three locations: an urban roadside site, an urban background site and a rural background site. Comparison of simultaneous measurements at the three sites allows for the estimation of an urban increment and roadside increment in PM following a Lenschow-type approach, which allows for simple modelling of city air pollution based on the urban and roadside increments in air pollution (Lenschow et al., 2001). The variation in measured PM with measured meteorological data is also discussed. Finally, we discuss the implications of using lowcost sensors in Nairobi and LMICs in general.

\section{Previous PM measurements in Nairobi}

In general, long-term air-quality monitoring in sub-Saharan Africa (SSA) is rare. Correspondingly, there are only limited PM data sets for East African urban areas; where data does exist, estimated concentrations for $\mathrm{PM}_{2.5}$ concentrations are approximately $100 \mu \mathrm{g} \mathrm{m}^{-3}$ compared to $<20 \mu \mathrm{g} \mathrm{m}^{-3}$ in most European and North American cities (Brauer et al., 2012). This indicates that urban PM air pollution in East Africa could be a significant health concern.

In Nairobi, there have been numerous short-term measurements of PM over the last decade (Brauer et al., 2012; Kinney et al., 2011; Ngo et al., 2015; Egondi et al., 2016; Gaita et al., 2016) with only one long-term continuous measurement (Gaita et al., 2014). To date, most measurements have used gravimetric measurement methodologies to record PM mass concentration in the $\mathrm{PM}_{2.5}$ and $\mathrm{PM}_{10}$ size fractions. Most measurements indicate that PM concentrations in Nairobi regularly exceed the WHO guidelines. At present, there is only one publication in the scientific literature describing the use of low-cost sensors in the measurement of PM (deSouza et al., 2017) that monitored air quality in Nairobi at six sites from May 2016 to January 2017. Using AlphaSense OPC-N2 instruments, the authors measured $\mathrm{PM}_{1}, \mathrm{PM}_{2.5}$ and $\mathrm{PM}_{10}$, as well as $\mathrm{NO}_{2}, \mathrm{NO}$ and $\mathrm{SO}_{2}$.

The study collected PM concentrations at six schools within Nairobi. It reported a $\mathrm{PM}_{2.5}$ concentration range between 11 and $21 \mu \mathrm{g} \mathrm{m}^{-3}$, and a range of 26 to $59 \mu \mathrm{g} \mathrm{m}^{-3}$ for $\mathrm{PM}_{10}$. The PM concentrations measured during the deSouza et al., 2017, study are noticeably lower than this study for both size fractions. It is worthy to note that the deSouza study collected measurements from May 2016 to January 2017, whereas this campaign took place from February to April 2017; the local meteorology may have influenced the discrepancies seen in both recorded PM concentrations. Additionally, the study did not calibrate the monitors, which leads to questions about absolute concentrations and interference from other environmental dependencies (Lewis and Edwards, 2016). The collected data from the study appeared noisy, with the authors stating they could not separate the signal from the noise without having access to an air quality measuring reference instrument (they recorded peaks at over $1000 \mu \mathrm{g} \mathrm{m}^{3}$ ). Despite the limitations, it provides a useful comparison to this calibrated study.

The paucity of long-term calibrated measurements has hindered the understanding of long-term trends and the influence of seasonal variations in meteorology and other factors. Most published data provide daily averages of PM mass; the lack of higher temporal resolution data precludes the generation of diurnal data, which can be useful for identifying individual sources of PM, in particular, vehicular PM that typically tracks traffic and hence peaks during rush hours.

The longest record of PM concentration in Nairobi is detailed in Gaita et al. (2014). In that work, the authors performed daily measurements of $\mathrm{PM}_{2.5}$ at an urban background and suburban site over a 2-year period from May 2008 to April 2010 using polycarbonate filters in a cyclone sampler. They reported a concentration range of 3 to $53 \mu \mathrm{g} \mathrm{m}^{-3}$ at the urban background site, with an overall mean of $21 \mu \mathrm{g} \mathrm{m}^{-3}$, which exceeds the annual WHO limit of $10 \mu \mathrm{g} \mathrm{m}^{-3}$ by a factor of 2. The average concentrations of $\mathrm{PM}_{2.5}$ at both sites were found to be $21 \pm 9.5$ and $13 \pm 7.3 \mu \mathrm{g} \mathrm{m}^{-3}$, respectively. Chemical composition measurements of the filter samples allowed source apportionment, via positive matrix factorization, to be carried out. The analysis suggested that five major source factors contribute to Nairobi $\mathrm{PM}_{2.5}$ : traffic, mineral dust, industry, combustion and a mixed factor. The dominant source factors were mineral dust and traffic, which accounted for $74 \%$ of the particle mass.

As an update to this study, Gaita et al. (2016) conducted a study on the characterization and size fractionation of PM and deposition fraction in the human respiratory system in Nairobi using measurements taken in August and September 2007, obtained at the University of Nairobi site. Based on the findings, the concentration levels of airborne PM sampled at the urban background site during the period was found to range between 1 and $78 \mu \mathrm{g} \mathrm{m}^{-3}$. The average $\mathrm{PM}_{2.5}$ con- 
centration at the site over the entire sampling period was $9.8 \pm 8.5 \mu \mathrm{g} \mathrm{m}^{-3}$.

A densely populated urban area with associated heavy local traffic within Nairobi largely contributes to the city's air pollution build-up. Kinney et al. (2011) investigated the impact of vehicular emissions in Nairobi on the concentration of $\mathrm{PM}_{2.5}$, observing a substantial range between 58 and $98 \mu \mathrm{g} \mathrm{m}^{-3}$ across an $11 \mathrm{~h}$ personal exposure along busy roadways and roundabouts. The range was estimated to be between 45 and $85 \mu \mathrm{g} \mathrm{m}^{-3}$ for a $24 \mathrm{~h}$ sampling due to pollutant dispersion at night. In addition, the study reported a decrease in horizontal dispersion measurements of $\mathrm{PM}_{2.5}$ from 128.7 to $18.7 \mu \mathrm{g} \mathrm{m}^{-3}$ over $100 \mathrm{~m}$ downwind of a major intersection in Nairobi. A vertical dispersion from street level to a third-floor rooftop in the Central Business District (CBD) showed a decrease in $\mathrm{PM}_{2.5}$ concentration from 119.5 to $42.8 \mu \mathrm{g} \mathrm{m}^{-3}$. This study clearly highlights that the PM concentration in Nairobi varies considerably over both time and space, which has significant implications for human exposure (see Discussion section).

Another study by Ngo et al. (2015) affirmed the contribution of anthropogenic activities on the quality of air in Nairobi. In their study, Teflon filters in $\mathrm{PM}_{2.5}$ samplers (BGI model 400) were used between 2 and 18 August 2011 and high concentrations of $\mathrm{PM}_{2.5}$ exposure levels among different groups in Nairobi were reported. According to the study, bus drivers in Nairobi city were exposed to about $103 \mu \mathrm{g} \mathrm{m}^{-3}$, while those in informal settlements, such as Mathare, reporting exposure levels of about $62.7 \mathrm{\mu g} \mathrm{m}^{-3}$, an indication that urgent measures are needed to be taken to mitigate the impact of air pollution in the city.

The severity of air pollution in urban centres in SSA is typically even higher in the informal settlements (slums), where acute respiratory tract infections and bronchitis are among the most frequent medical diagnoses (Gulis et al., 2004). Egondi et al. (2016), in their study on air pollution in two informal settlements in Nairobi: Korogocho and Viwandani, reported higher levels of $\mathrm{PM}_{2.5}$ in the two slums. Optical counters (TSI DustTrak II model 3530) were used in the study and observed average levels of $\mathrm{PM}_{2.5}$ in Korogocho slum, lying west of Dandora, Nairobi's biggest dumping ground, were the highest at $166 \mu \mathrm{g} \mathrm{m}^{-3}$ and Viwandani, situated north of Nairobi, recorded $67 \mu \mathrm{g} \mathrm{m}^{-3}$.

\section{Methodology}

\subsection{Site locations}

This study used three field sites in Kenya (see Fig. 1). Two sites were in Nairobi, which is the capital of Kenya, covering an area of ca. $696 \mathrm{~km}^{2}$ and home to approximately $3.5 \mathrm{mil}-$ lion residents according to a World Population review conducted in 2016 (Kenya Population, 2016), making it the second most populated city in East Africa after Dar es Salaam,
Tanzania. In addition to Nairobi's longstanding popularity as a travel destination, due to its safari and other holiday resorts, the city also acts as East Africa's diplomatic, financial and communication capital (Rajé et al., 2017).

Its geographical location is at approximately $1.29^{\circ} \mathrm{S}$ and $36.82^{\circ} \mathrm{E}$. The highest elevation point in the city is at an altitude of $1663 \mathrm{~m}$ above the ground. As discussed in the introduction, Nairobi is undergoing rapid increases in population and motorization both of which will likely lead to greater PM pollution in the absence of any efforts of mitigation against the pollution. Other significant infrastructure projects such as major road building are currently being undertaken, which will also likely lead to increased PM loadings. Within Nairobi, the two field sites represent an urban background location and an urban roadside location. The other site, a rural background site, is located on the outskirts of Nanyuki, a town that is located at an approximate aerial distance of $147 \mathrm{~km}$ to the north-northeast of Nairobi and $240 \mathrm{~km}$ by road. The sensor boxes were placed in locations free from obstacles, at the three measurement sites, allowing for $360^{\circ}$ of air flow. A description of the meteorological conditions is provided in the Supplement.

\subsubsection{Site 1: American Wing, University of Nairobi, Nairobi (urban background site)}

The first site for data collection in Nairobi was at the American Wing building located in the University of Nairobi, standing at an elevation of $17 \mathrm{~m}$ a.g.l. Air flow at the site was free from any obstruction as the OPCs were located at an elevated point above the ground. The nearest road is Harry Thuku Road, which has very few on-road vehicles (no heavy trucks) and it leads to Fairmont The Norfolk and Boulevard hotels, and Kijabe Street.

\subsubsection{Site 2: Tom Mboya Street, fire station, Nairobi (urban roadside)}

The second collection site in Nairobi was at the fire station, which is located within the CBD in the city. Unlike the American Wing site, the area around the fire station is characterized by high traffic flow which includes common public transport vans, locally known by the name "matatus". It is on an urban street canyon, on a street where smoking diesel vans are frequent and is exposed to urban heat island effects. It is also in the neighbourhood of a vertical dispersion measurement site of $\mathrm{PM}_{2.5}$ used by Kinney et al. (2011). The monitor was mounted at a height of approximately $5 \mathrm{~m}$.

\subsubsection{Site 3: Nanyuki town (rural background)}

The third site chosen was on the outskirts of Nanyuki town, an administrative town in Laikipia County, which is located to the northwest of Mt Kenya. The town is positioned at the Equator at approximately $1.28^{\circ} \mathrm{S}$ and $36.01^{\circ} \mathrm{E}$. The highest point in Nanyuki is at an elevation of $2000 \mathrm{~m}$ a.g.l. The 
town is home to approximately 50000 people as per the last census conducted (KNBS, 2015). The Nanyuki region has a hinterland of significant agricultural cultivation, forest and considerable grazing activities (Gatari et al., 2005). The OPC was hung about $4 \mathrm{~m}$ a.g.l. thus exposing it to free regional air mass in an area of minimal local influence.

\subsection{PM measurement equipment}

Small low-cost optical particle sensors (AlphaSense, OPC$\mathrm{N} 2$, firmware version 18) were used to measure PM concentrations. The OPC-N2 is a miniaturized OPC, which has dimensions of $75 \mathrm{~mm} \times 60 \mathrm{~mm} \times 65 \mathrm{~mm}$ and weighs under $105 \mathrm{~g}$. The unit cost of an OPC-N2 is approximately GBP 250 or KES 25000 ; hence it is significantly cheaper than reference OPC instruments which cost approximately 30-50 times as much. Reference-grade gravimetric instruments can cost even more. The lower cost of the OPC-N2 provided the opportunity for measurements at multiple sites simultaneously. It measures particles in the reported size range of 0.38 to $17 \mu \mathrm{m}$ across 16 size bins, with a maximum particle count of 10000 per second. The particle number concentration is converted by on-board factory calibration to PM concentrations according to European Standard EN481 (OPC-N2 manual).

The assumed density for all particle sizes is $1.65 \mathrm{~g} \mathrm{~cm}^{-3}$ and no special weighting is placed on any particular bin size. However, the manual for the OPC states "an additional weighting is applied on units with Firmware 18 or higher to account for under counting at low particle sizes and the effect of carbon particles in urban air so that the output matches collocated reference detectors."

The lower cut-off for particle size observed by the OPC is $380 \mathrm{~nm}$ and hence a large proportion of all particles are not observed by the OPC due to the particle number being dominated by the smallest particle sizes (Seinfield and Sypyros, 2016). Ultrafine particles (particles of aerodynamic diameter $<100 \mathrm{~nm}$ ) were therefore not measured. However, the interest of the study was particulate mass which is dominated by particle sizes that were measured.

The sensors had their data logged using Raspberry Pi 3 minicomputers. The Python script used to run the OPC-N2 on the Raspberry Pi 3 is discussed and provided in Crilley et al. (2018) and makes use of the py-opc python library for operating the OPC-N2 written by Hagan (2017). Together, the OPC-N2, minicomputer and accompanying wires and tubing were placed in bespoke weather-resistant housing (dimensions ca. $30 \mathrm{~cm} \times 20 \mathrm{~cm} \times 10 \mathrm{~cm}$ ). Power for both the OPCN2 and minicomputer were provided by mains power.

The OPC-N2 sensors are factory calibrated to measure PM mass concentrations representative of the UK. However, in our previous study (Crilley et al., 2018), we demonstrated that in situ calibration of the sensors is required for the correct measurement of PM mass concentrations at urban background sites in Birmingham, UK. The calibration in the Cril- ley et al. (2018) study involved both scaling and a relative humidity $(\mathrm{RH})$ dependent term for when the RH is greater than approximately $85 \%$.

The mass concentrations from the OPC-N2 devices, in the $\mathrm{PM}_{1}, \mathrm{PM}_{2.5}$ and $\mathrm{PM}_{10}$ size bins were recorded in time intervals of $10 \mathrm{~s}$. For the subsequent analysis, the mass concentration data were aggregated into $1 \mathrm{~h}$ time bins using the mean average. In time periods which contained missing data, the mean average of the available data was aggregated. All data manipulations were performed using $\mathrm{R}$ (version 3.4.1), and the openair project package for $\mathrm{R}$ was extensively used for data visualization (Carslaw and Ropkins, 2012).

\subsection{Meteorological station}

The local meteorology for Nairobi was measured at the same location as the urban background site using a Vaisala instrument (WXT510) with the following variables measured: wind speed, wind direction, temperature, relative humidity, barometric pressure and rainfall with an instrument temporal resolution of 5 minutes. The measured meteorology parameters were in good agreement with other local measurements such as those observed at Jomo Kenyatta International Airport (JKIA), which is approximately at an aerial distance of $10 \mathrm{~km}$. The proximity of the meteorological station at the urban background site to the urban roadside makes the meteorological data appropriate for both sites. The data were collected at the urban background site from the 2 February to the 6 April 2017, covering the duration of the PM measurements.

\subsection{OPC-N2 gravimetric mass calibration}

The OPC-N2 mass concentrations were calibrated using gravimetric measurements of $\mathrm{PM}_{2.5}$ and $\mathrm{PM}_{10}$. The gravimetric calibration measurement was carried out on the 9 February 2017 for $24 \mathrm{~h}$. A collocation measurement of the OPC and an Anderson dichotomous impactor (Sierra Instruments Inc., USA) was set up, on the only possible date, at the background site. The impactor collected $\mathrm{PM}_{2.5}$ and $\mathrm{PM}_{10-2.5}$ particles on Teflon filters (diameter $=37 \mathrm{~mm}$, pore size $=2 \mu \mathrm{m})$ at a total flow rate of $1 \mathrm{~m}^{3} \mathrm{~h}^{-1} . \mathrm{PM}_{10}$ is therefore the sum of the two size fractions $\left(\mathrm{PM}_{2.5}+\mathrm{PM}_{10-2.5}\right)$. The chosen sample day was rain free and had similar temperature and RH profiles compared to the rest of the OPC sampling campaign. The filters were weighed using a mass balance before and after PM collection. The observed $24 \mathrm{~h}$ average mass concentrations of $\mathrm{PM}_{2.5}$ and $\mathrm{PM}_{10}$ from the impactor were $27.6 \pm 6.8$ and $51.8 \pm 10.3 \mu \mathrm{g} \mathrm{m}^{-3}$, respectively, while those recorded from the OPC were 16.9 and $30.6 \mu \mathrm{g} \mathrm{m}^{-3}$, respectively. The uncertainty in gravimetric concentrations was estimated from the instrument $(10 \%)$, sampling $(7 \%)$ and weighing $(25 \%)$ errors, and that of the OPC data was the standard deviation. The value is as provided by the OPC, it is not possible to provide an error from the 1-day calibration. From Crilley et al. (2018), the coeffi- 


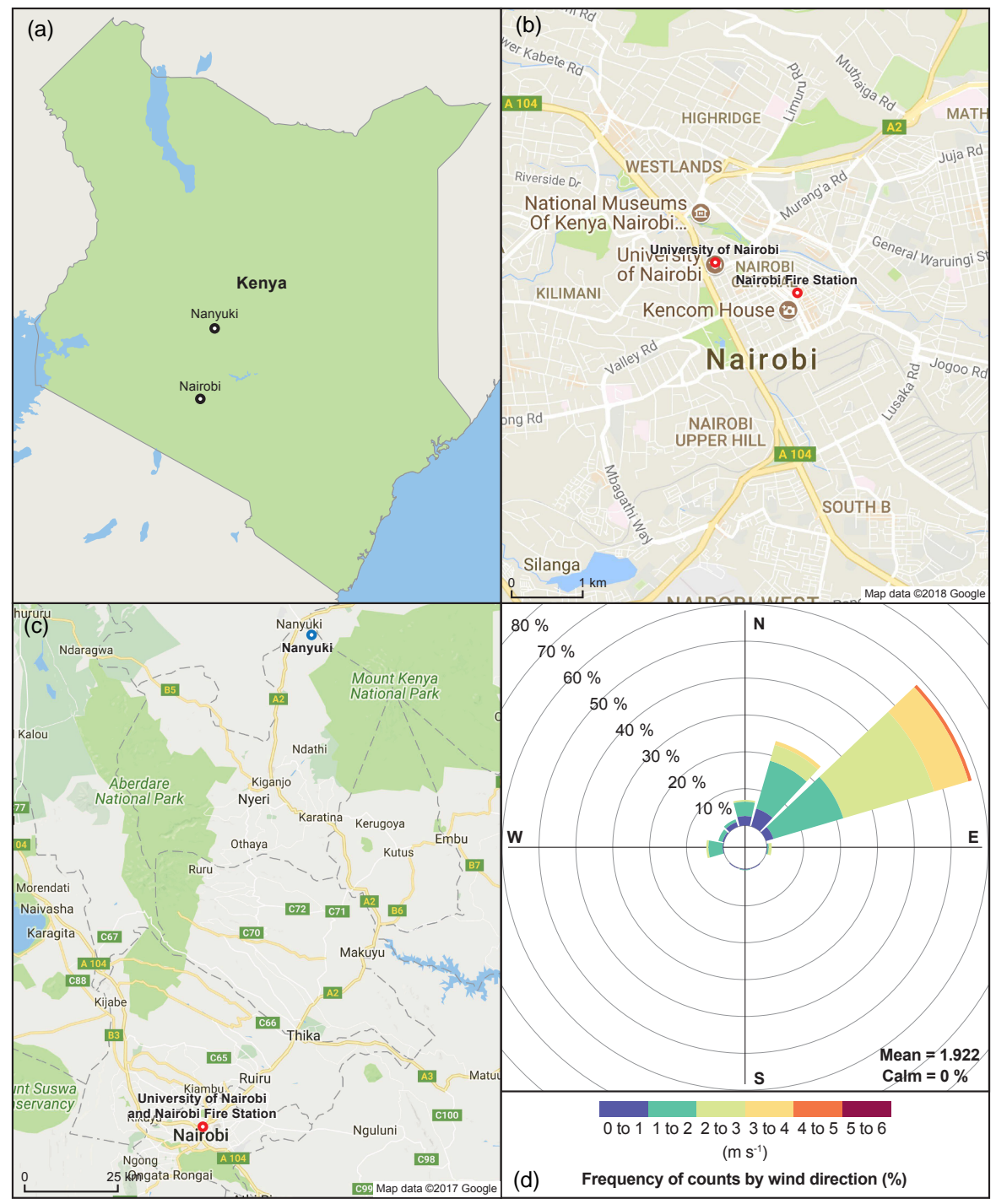

Figure 1. Locations of data collection sites and wind rose for the urban background location. (a, c) Locations of Nairobi and Nanyuki in Kenya. Panel (b) shows relative locations of urban background locations (University of Nairobi, American Wing) and urban roadside location (Nairobi fire station). (d) Wind rose generated from data collected at the urban background location during the measurement campaign.

cient of variance is estimated as $0.32 \pm 0.16,0.25 \pm 0.14$ and $0.22 \pm 0.13$ for $\mathrm{PM}_{1}, \mathrm{PM}_{2.5}$ and $\mathrm{PM}_{10}$ mass concentrations, respectively. Hence, the observed scaling factors between the OPC-derived masses and gravimetric analysis were 1.70 and 1.63 for $\mathrm{PM}_{10}$ and $\mathrm{PM}_{2.5}$, respectively. These factors are different to those observed in Crilley et al. (2018), which performed a similar gravimetric calibration procedure with the OPC-N2 measuring PM at an urban roadside site in the UK. The discrepancies in scaling factors are likely due to differences in average particle densities observed in Kenya compared to those observed in the UK, and also the typical RH measured in Nairobi compared to the UK measurements (see the discussion in Sect. 3.5). In particular, Nairobi PM has been shown to have a high percentage of mineral dust which typically has a high density, with Gaita et al. (2014) showing the annual average composition of $\mathrm{PM}_{2.5}$ being composed of $35 \%$ mineral dust which originates from unpaved roads and wind-blown dust during the dry seasons. The gravimetric analysis did not allow for the calibration of the $\mathrm{PM}_{1}$ mass concentrations because a filter sample was not generated for the fraction of PM in this size range. Hence, the $\mathrm{PM}_{1}$ size fraction calibration uses the same calibration factor derived for the $\mathrm{PM}_{2.5}$ size fraction.

The gravimetric calibration was carried out at the urban background field location for the three OPC-N2s which were subsequently used in the measurement campaign at the three field sites. Hence, the calibration was most appropriate for the urban background site. Whilst the urban roadside site is 
in close proximity to the urban background site, the roadside site is more influenced by traffic-related PM; hence, the average particle density at the roadside site is likely different to the urban background site. Likewise, the rural background site is likely to be far more influenced by mineral dust than the two urban sites. Hence the gravimetric calibration at the urban background sites only provides an estimate calibration for the urban roadside and rural background sites.

Only one gravimetric calibration was carried out during the study period due to the lack of resources for further calibrations. If the PM composition varied significantly over the study period, then the true calibration factor will also change. Hence, the calibration factor used should be treated as an estimate for the whole study period because changes in PM composition lead to changes in particle refractive index, and therefore the scattering pattern which is measured by the OPC to estimate particle size. Changes in particle density, due to compositional changes, also affects the particle mass calculated from the particle size. It is noted that for future studies it would be beneficial to have multiple gravimetric calibration points to check for continuing accuracy of the OPC-N2 sensors throughout the campaign.

\subsection{Measured particle mass dependence on relative humidity}

As detailed in Crilley et al. (2018), under UK conditions, the OPC-N2 device is sensitive to variations in $\mathrm{RH}$ when the $\mathrm{RH}$ exceeds ca. $85 \%$. Crilley et al. (2018) suggest the RH dependence is due to the hygroscopic properties of particles that result in significant water mass being taken up by PM at high $\mathrm{RH}$. This hygroscopic dependence can be modelled using a calibration that uses the $\kappa$-Kohler parameterization of aerosol hygroscopicity (Petters and Kreidenweis, 2008). The average $\kappa$ parameter values for Africa $(\kappa=0.15 \pm 0.12)$ are lower than for Europe $(\kappa=0.36 \pm 0.16)$, as based on the Pringle et al. (2010) model, which is in good agreement with observational data. It is noted that composition of urban PM will have different hygroscopic properties to the average rural background. However, PM derived from urban emissions are often less hygroscopic than rural PM; therefore, the rural estimates might provide a useful upper estimate of particle hygroscopicity in urban centres. All locations used in the study period typically have RH less than the $85 \%$ threshold. However, it is noted that the RH dependent measurements shown in Crilley et al. (2018) were performed in the UK, whereas these measurements were performed in Kenya. There may be significant differences between aerosol compositions, and hence hygroscopicities, in these two countries albeit both urban areas (Birmingham and Nairobi) will have significant vehicular influence. Measurements of RH at the Kenyan urban background site show that RH was only equal to or greater than $85 \%$ less than $1 \%$ of the time. Furthermore, there is no significant dependence of either the observed $\mathrm{PM}_{2.5}$ or $\mathrm{PM}_{10}$ mass concentration upon RH (see Supplement Fig. S1a and b), this is consistent with low hygroscopicity aerosols. The measurement period of work reported in this paper was in the Kenyan dry season with very few rain events, it is noted that if low-cost sensors are to be used in the wet season in Kenya then the RH will probably be greater than $85 \%$ during significant periods and the hygroscopicity effect will likely need to be accounted for to obtain good measurements.

\section{Results}

\subsection{Particulate matter measurement}

PM data were collected at the three sampling sites over the time period inclusive of 2 February and 24 March 2017. Figure 2 provides the time series data for the $\mathrm{PM}_{10}, \mathrm{PM}_{2.5}$ and $\mathrm{PM}_{1}$ data over the whole measurement campaign. Gaps in data at specific sites are either due to the co-location of two or all three instruments at one site for cross calibration purposes, due to power failure requiring instrument restart or OPC malfunctioning.

The inter-instrument $\mathrm{OPC}-\mathrm{N} 2$ precision was measured once during the campaign by co-locating the three instruments at the urban background site for 3 days for side by side sampling. The three instrument co-location was carried out during at the start of the campaign (16-18 February 2017). Two OPCs were collocated together at the urban roadside site near the end of the campaign (4-27 March 2017). All instruments gave very similar readings during both co-location periods, the inter-instrument precision gave a coefficient of variance of $8.8 \pm 2.0 \%$ in the $\mathrm{PM}_{2.5}$ fraction, with no degradation in inter-instrument precision observed over the sampling period. This coefficient of variance is better than observed in Crilley et al. (2018) but this is expected because of the lower RH conditions in Nairobi (see previous discussion).

Continuous monitoring at all three sites was achieved for a fortnight in the period 18 February to 4 March 2017. This period will henceforth be referred to as the intensive period, whereas the total measurement campaign will be referred to as the campaign period. The number of monitoring days for the urban roadside, urban background and rural background monitoring sites during the campaign period were 40,29 and 25 days, respectively.

Table 1 provides the average $\mathrm{PM}_{1}, \mathrm{PM}_{2.5}$ and $\mathrm{PM}_{10}$ mass concentrations observed at the three sites during the campaign period. An identical table for the intensive period is included in the Supplement (see Table S1). The percentage of daily exceedances of daily $\mathrm{PM}_{2.5}$ and $\mathrm{PM}_{10}$ as per WHO guidelines are also provided; however, to date there is no set guidelines of $\mathrm{PM}_{1}$. All measurement sites exceeded the WHO daily guidelines for both $\mathrm{PM}_{2.5}$ and $\mathrm{PM}_{10}$ for some of the days sampled. The urban roadside site exceeds the WHO guidelines on most days $\left(85 \%\right.$ for $\mathrm{PM}_{2.5}$ and $90 \%$ for $\left.\mathrm{PM}_{10}\right)$. Furthermore, on many days (13\% for $\mathrm{PM}_{2.5}$ and $40 \%$ for $\left.\mathrm{PM}_{10}\right)$ the urban roadside site exceeds the WHO 

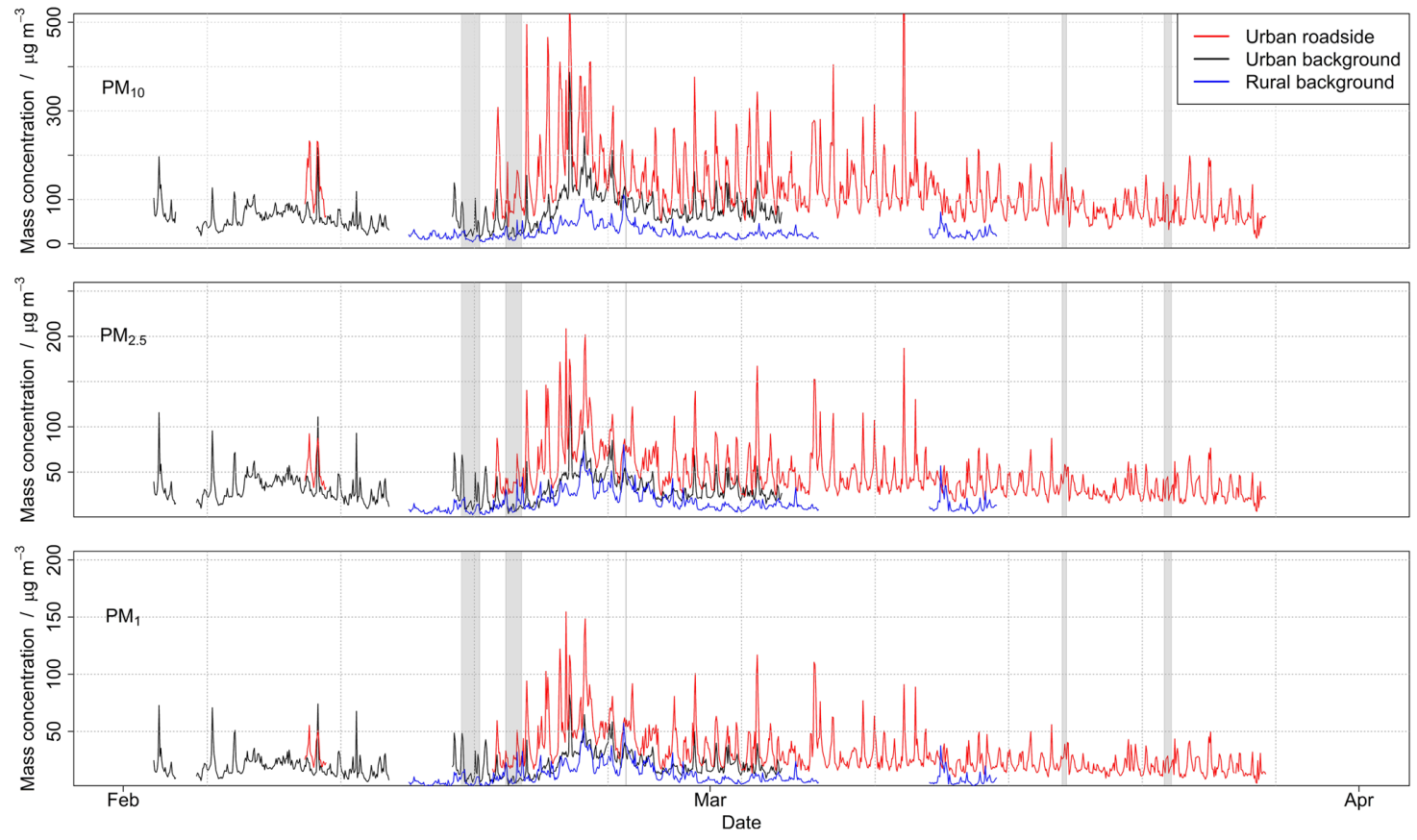

Figure 2. Hourly time series data showing $\mathrm{PM}_{10}, \mathrm{PM}_{2.5}$ and $\mathrm{PM}_{1}$ mass concentrations at the three study locations. Red line is the urban roadside, black line is the urban background and blue line is the rural background. Where multiple OPC-N2 devices were measuring in the same location at the same time, the average is provided. The grey shading represents rain events as measured at the urban background location.

guidelines by at least twice as much. The urban background site has fewer exceedances, compared to the urban roadside site, with daily exceedances occurring approximately onethird of the time. The urban background site is at an elevated position, which largely removes the direct influence of local sources of PM pollution. As such, it can be assumed that the PM mass concentrations observed at this location represent a lower limit for the ground level PM concentrations throughout Nairobi, since most PM emissions will be due to ground level sources such as vehicle emissions, fires, local industry and others. The rural background site has no daily exceedances in the $\mathrm{PM}_{10}$ size fraction but exceeds the $\mathrm{PM}_{2.5}$ guidelines $12 \%$ of the time.

During the 2-week intensive campaign, there was a period of elevated PM mass concentration observed in $\mathrm{PM}_{1}$, $\mathrm{PM}_{2.5}$ and $\mathrm{PM}_{10}$ size fractions centred around the 23 February. The elevated PM was observed in all three sites; therefore, this might represent a long-range pollution event. Correspondingly, the average PM mass concentrations and percentage of WHO exceedances are higher during the intensive period compared to the whole measurement campaign (see Table S1).

Whilst there is insufficient temporal data to provide a yearly average value for $\mathrm{PM}_{2.5}$ and $\mathrm{PM}_{10}$ mass concentrations for the three sites, the annual average values can be estimated from the data set using the average values provided in Table 1 . These values are likely to be upper esti- mates for the yearly values because the measurements were obtained in the period with little precipitation, thereby minimizing the degree of wet deposition of the PM. For instance, Gaita et al. (2014) showed that Nairobi's short rainy season (typically October-December) suppresses PM concentrations at the urban background site by approximately $50 \%$. Notwithstanding the seasonal rain consideration, the average PM mass concentration observed in this study suggests that the WHO recommendations for annual $\mathrm{PM}_{2.5}$ and $\mathrm{PM}_{10}$ are likely exceeded at both the urban background and urban roadside locations. For the urban background site, the measured average $\mathrm{PM}_{2.5}$ and $\mathrm{PM}_{10}$ mass concentrations exceed the annual WHO recommendations by factors of 2.5 and 2.7, respectively. Whereas for the urban roadside site they exceed recommendations by 3.7 and 4.7, respectively. These significant exceedances for both the urban roadside and urban background sites suggests that most of Nairobi's population will be subjected to outdoor air pollution far in excess of the WHO recommendations for annual exposure. Figure 3 provides the box and whisker plots for the hourly averaged $\mathrm{PM}_{2.5}$ and $\mathrm{PM}_{10}$ data for the three measurement sites. Figure $\mathrm{S} 3$ provides box and whisker plots for the daily averaged $\mathrm{PM}_{2.5}$ and $\mathrm{PM}_{10}$ data for the three measurement sites and highlights the proportion of the days which exceed the WHO annual and daily recommendations.

Figure 4 provides the mean average diurnal hourly profiles of the $\mathrm{PM}_{1}, \mathrm{PM}_{2.5}$ and $\mathrm{PM}_{10}$ mass concentrations for 
Table 1. Mean average PM mass concentrations $\left(\mathrm{PM}_{1}, \mathrm{PM}_{2.5}\right.$ and $\left.\mathrm{PM}_{10}\right)$ and daily exceedances of the WHO PM guidelines $\left(\mathrm{PM}_{2.5}\right.$ and $\mathrm{PM}_{10}$ ) observed at the three measurement sites during the campaign period.

\begin{tabular}{|c|c|c|c|c|c|c|}
\hline $\begin{array}{l}\text { Measurement } \\
\text { location }\end{array}$ & $\begin{array}{r}\text { Measurement } \\
\text { days (number) }\end{array}$ & $\begin{array}{r}\text { Average } \mathrm{PM}_{1} \\
\text { mass concentration } \\
\left(\mu \mathrm{g} \mathrm{m}^{-3}\right)\end{array}$ & $\begin{array}{r}\text { Average } \mathrm{PM}_{2.5} \\
\text { mass concentration } \\
\left(\mu \mathrm{g} \mathrm{m}^{-3}\right)\end{array}$ & $\begin{array}{r}\text { Average } \mathrm{PM}_{10} \\
\text { mass concentration } \\
\left(\mu \mathrm{g} \mathrm{m}^{-3}\right)\end{array}$ & $\begin{array}{r}\% \text { daily } \\
\mathrm{PM}_{2.5} \\
\text { exceedances* }\end{array}$ & $\begin{array}{r}\% \text { daily } \\
\mathrm{PM}_{10} \\
\text { exceedances* }\end{array}$ \\
\hline Urban background & 29 & 16.1 & 24.8 & 53.0 & 31.6 & 39.5 \\
\hline Urban roadside & 40 & 23.9 & 36.6 & 93.7 & 85.0 & 90.0 \\
\hline Rural background & 25 & 8.8 & 13.0 & 19.5 & 12.0 & 0.0 \\
\hline
\end{tabular}

* WHO guidelines for daily $\mathrm{PM}_{10}$ and $\mathrm{PM}_{2.5}$ are 50 and $25 \mu \mathrm{g} \mathrm{m}{ }^{-3}$, respectively.
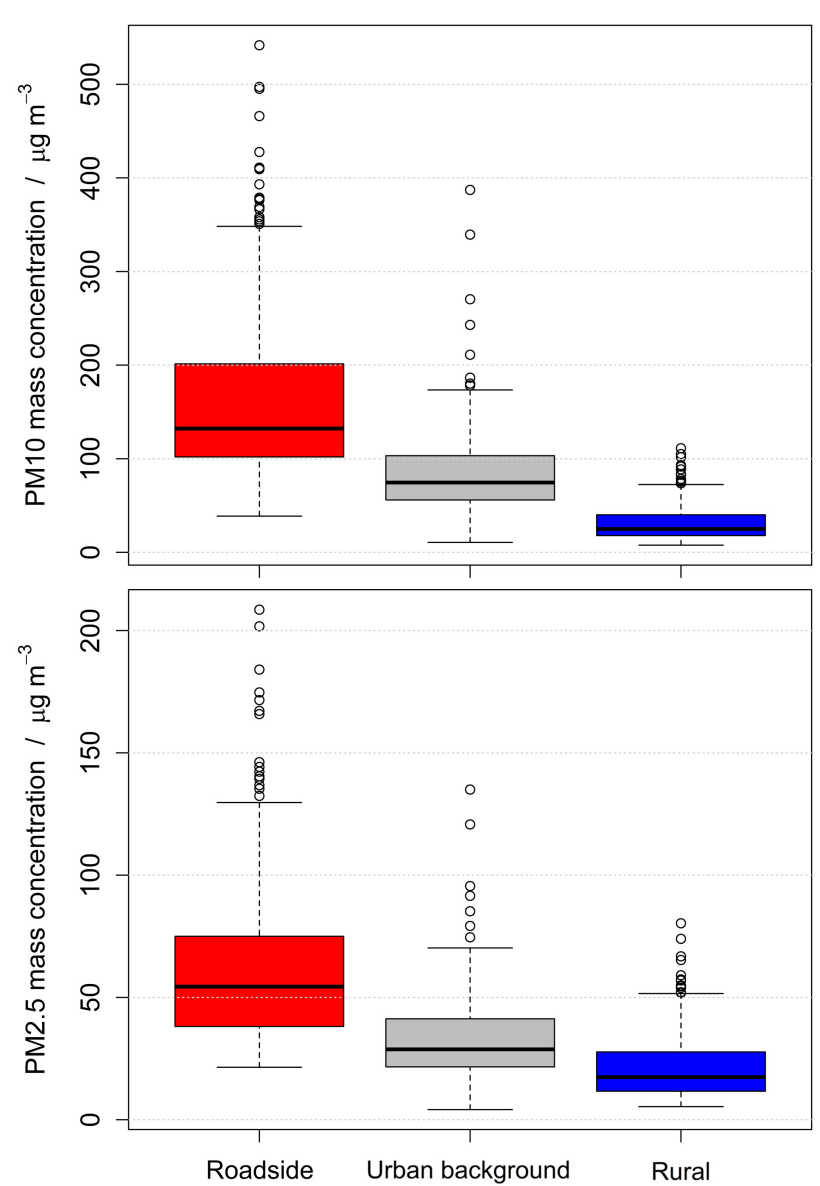

Figure 3. Box and whisker plots of the hourly averaged $\mathrm{PM}_{2.5}$ and $\mathrm{PM}_{10}$ mass concentrations measured at the three sites.

the three measurement sites during the whole campaign period. There is clear diurnal variation observed at all the sites, two distinct peaks are observed in the two urban locations during the morning (ca. 05:00-10:00 EAT) and the evening (ca. 18:00-24:00), which correspond to the Nairobi peak traffic periods. The normalized data shows that the traffic-related structure is very similar in both the urban background and urban roadside sites indicating that the traffic-related PM pollution is the dominant source at both sites. The rural back- ground site also shows diurnal variation with some indication of a traffic-related signal at similar times to the urban sites, especially in the $\mathrm{PM}_{2.5}$ size fraction. However, overall the rural diurnal cycle appears to largely correspond to solar insolation suggesting the dominant factor affecting the rural mass concentrations is the height of the local boundary layer, which decreases in the night time and increases with greater solar insolation.

Through comparison of the urban roadside, urban background and rural background hourly averaged data, it is possible to generate estimates of urban increments and roadside increments relevant for Nairobi using a Lenschow-type approach (Lenschow et al., 2001). For the intensive period, the urban and rural increments are calculated for the $\mathrm{PM}_{1}, \mathrm{PM}_{2.5}$ and $\mathrm{PM}_{10}$ mass concentrations (see Fig. 5). The urban increment is calculated by subtracting the hourly average values of the rural background site from the urban background site. During the intensive period, analysis of the air mass backtrajectories indicates that the regional wind direction was almost exclusively from the northeast. Hence the Nanyuki rural background site is a good representative of the rural background that impacts upon Nairobi.

The roadside increment was calculated by subtracting the hourly average values of the urban background site from the urban roadside site. It is noted that the chosen roadside measurement site is particularly busy with vehicles, compared to many other non-highway streets in Nairobi. In particular, the site is a popular matatu (14 seat passenger vans) terminal with multiple vehicles idling at any point during the day. Therefore, the roadside increment obtained using this location likely represents a value close to the upper boundary for Nairobi roads.

The urban and roadside increments are significant for all the investigated PM size fractions. A statistical summary of the roadside and urban increments for the $\mathrm{PM}_{1}, \mathrm{PM}_{2.5}$ and $\mathrm{PM}_{10}$ size fractions are given in Table 2.

During the intensive period, the mean average roadside increment is $57.2 \%, 47.5 \%$ and $48.1 \%$ of the mean roadside mass concentration, in the $\mathrm{PM}_{1}, \mathrm{PM}_{2.5}$ and $\mathrm{PM}_{10}$ size fractions, respectively.

The spatial variation in PM emissions, in the different size fractions, can be assessed at the urban background and ur- 
(a)

(b)
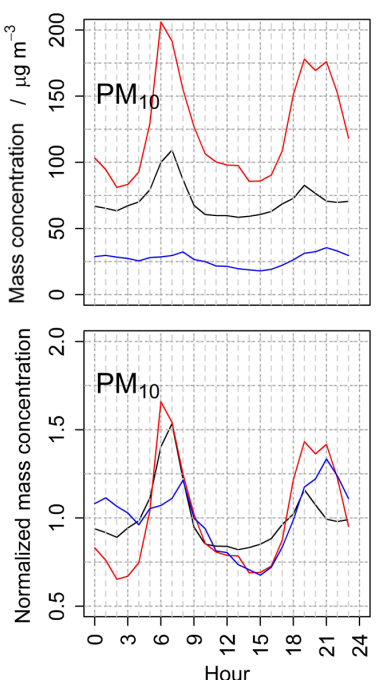
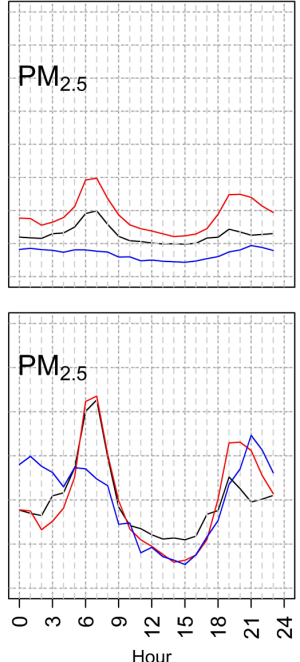
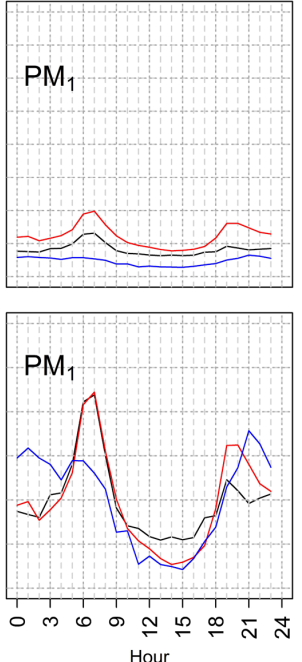

Figure 4. Diurnal variation in $\mathrm{PM}_{10}, \mathrm{PM}_{2.5}$ and $\mathrm{PM}_{1}$ mass concentration measured at the three field sites during the whole campaign period. (a) shows the measured concentrations. (b) shows the mass concentrations that have been normalized to the average mass concentration.

Table 2. Summary of roadside and urban increments for the $\mathrm{PM}_{1}, \mathrm{PM}_{2.5}$ and $\mathrm{PM}_{10}$ size fractions measured during the intensive period.

\begin{tabular}{lrrr|rrr}
\hline & \multicolumn{3}{c}{ Roadside increment $\left(\mu \mathrm{g} \mathrm{m}^{-3}\right)$} & \multicolumn{3}{|c}{ Urban increment $\left(\mu \mathrm{g} \mathrm{m}^{-3}\right)$} \\
\cline { 2 - 7 } & $\mathrm{PM}_{1}$ & $\mathrm{PM}_{2.5}$ & $\mathrm{PM}_{10}$ & $\mathrm{PM}_{1}$ & $\mathrm{PM}_{2.5}$ & $\mathrm{PM}_{10}$ \\
\hline Minimum & -4.3 & -6.1 & -31.7 & -20.1 & -26.9 & -23.6 \\
1st quartile & 7.3 & 10.5 & 22.2 & 1.0 & 2.2 & 19.5 \\
Median & 12.6 & 18.3 & 43.3 & 4.7 & 7.1 & 33.1 \\
Mean & 18.9 & 22.9 & 58.1 & 5.2 & 8.2 & 36.6 \\
3rd quartile & 20.7 & 30.0 & 83.4 & 8.7 & 13.2 & 48.2 \\
Maximum & 95.5 & 123.9 & 292.6 & 51.2 & 86.3 & 258.0 \\
\hline
\end{tabular}

ban roadside sites using bivariate polar plots, which provide information on the variation in PM mass concentration with wind direction and speed (see Fig. 6; Carslaw and Beevers, 2013). The urban background and urban roadside sites are sufficiently closely collocated $(<0.5 \mathrm{~km}$ apart $)$ that the wind data acquired at the urban background site is applicable to the urban roadside site. Wind direction data were not available for the rural background site, so analysis of the spatial variation was impossible at this site.

Figure 6 clearly shows significant variation in PM mass concentration at both urban sites, which are dependent upon the wind conditions. The urban background site shows broadly similar behaviour in the spatial variation in the $\mathrm{PM}_{1}$, $\mathrm{PM}_{2.5}$ and $\mathrm{PM}_{10}$ size fractions. The peak in concentrations are observed at low wind speeds and when the wind comes from the west and south. This wind direction dependence is consistent with the close proximity of the major highway A104 "Nairobi-Malaba Road", which passes close to the site in the direction of high PM concentrations. The diurnal profiles and roadside increments discussed earlier combined with the wind dependence highlights the role of roads in Nairobi as the major source of PM in all size fractions studied. Since the site is within Nairobi's CBD, there are other significant roads nearby as well, but the A104 has the greatest fleet density.

The urban roadside site also shows distinct variation in pollutant concentrations with wind speed and direction. In the $\mathrm{PM}_{10}$ size fraction, the greatest concentrations are seen to the northwest and smallest to the southwest with a steady reduction between these two extremes. The $\mathrm{PM}_{2.5}$ and $\mathrm{PM}_{1}$ size fractions show a more complex behaviour with highest concentrations at low wind speeds and the north and west directions. The urban roadside location is surrounded by small roads and lower traffic speeds compared to the highways, for example the A104. The lower traffic speeds likely lead to less non-exhaust-pipe emissions from dust resuspension and hence there are less local $\mathrm{PM}_{10}$ particles when compared to the urban background site. Whereas the localized $\mathrm{PM}_{2.5}$ and $\mathrm{PM}_{1}$ concentrations are likely due to the heavily congested local roads on which matatus and other vehicles are often left idling leading to high exhaust-pipe emissions, which are 

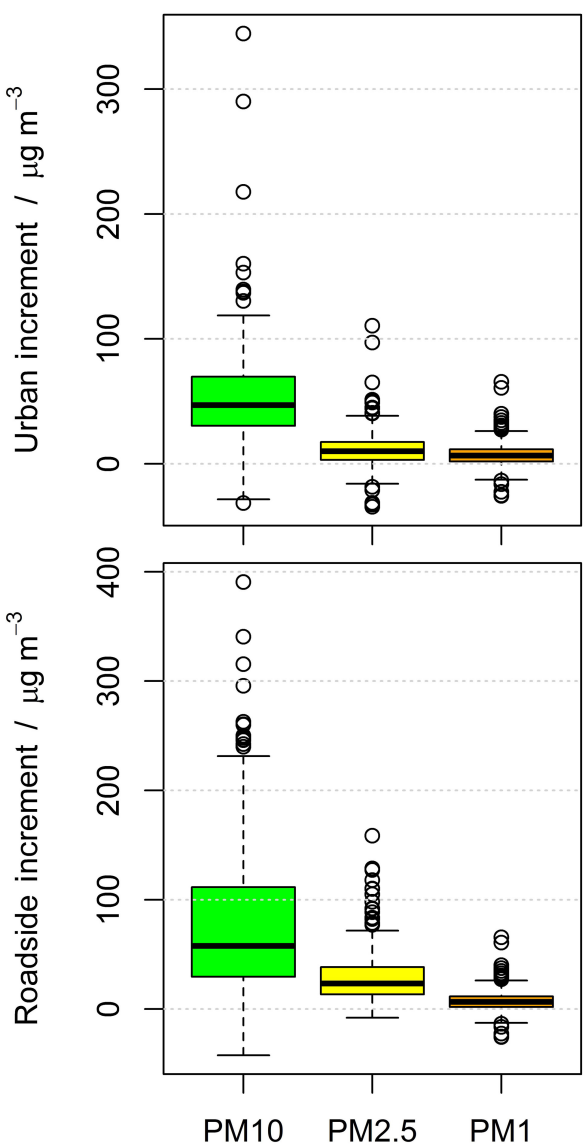

Figure 5. Box and whisker plots of urban and roadside increment of $\mathrm{PM}_{10}, \mathrm{PM}_{2.5}$ and $\mathrm{PM}_{1}$ calculated for Nairobi. Data were taken from the intensive campaign period when the urban background, urban roadside and rural background sites were all measuring simultaneously. Hourly averaged mass concentration data are used.

typically in the smaller PM size fractions (Pant and Harrison, 2013).

Figure 7 provides the distributions of the ratio between the coarse and the fine PM mass fractions at the three field sites during the campaign period. Whilst each site shows distinct variation (with large interquartile ranges) in the reported coarse to fine ratio - which is dependent on the time of year and time of day - the median ratios at each site are distinct, with the ratio at the urban roadside, urban background and rural background sites being 1.6, 1.3 and 0.5 , respectively. At the roadside site, the median coarse to fine mass ratio is almost triple that observed at the rural background; this is consistent with the dominant source of PM at the roadside site being the resuspension of large dust particles. At the rural site, the PM size distribution has a greater ratio of fine material consistent with the rural site having a signature of regional background PM. The ratio of coarse to fine PM at the urban background site is intermediate between the roadside and rural background sites, which suggests that this site is significantly effected by both the regional background and the urban road PM sources. These insights into the coarse to fine PM ratio are consistent with the roadside and urban increments, shown in Fig. 5 and discussed previously.

\subsection{Comparison with previous measurements}

To the best of our knowledge, there has been no previous literature study to date using calibrated low-cost sensors to measure PM in Nairobi. Furthermore, it is difficult to make a comparison with previous PM studies in Nairobi because of the differences in the temporal resolution of the data and campaign durations used in this study compared to past measurements.

The most comparable study of $\mathrm{PM}_{2.5}$ would be the work of Gaita et al. (2016), which also recorded the levels of $\mathrm{PM}_{2.5}$ at the University of Nairobi (urban background site). The urban background average of $\mathrm{PM}_{2.5}$ during this study's campaign period was $24.8 \mathrm{\mu g} \mathrm{m}^{-3}$ compared to the Gaita et al. (2016) mean average of $9.8 \mu \mathrm{g} \mathrm{m}^{-3}$, showing a significant increase of $253 \%$. The sampling time window used in the Gaita et al. (2016) study was between August and September 2007, which is distinct from the February to March 2017 period of this study. Both of these study periods were largely dry, with low precipitation levels, thereby suggesting PM deposition would have been similar between the two studies. The significant increase in measured $\mathrm{PM}_{2.5}$ could be due to several reasons. Firstly, there could be seasonal differences between August/September and the February/March sampling periods of the two studies; however, the study of Gaita et al. (2014) suggests the urban background concentrations of $\mathrm{PM}_{2.5}$ mass concentration is similar between these two time periods. The regional background PM loading may have increased during this time period, potentially due to increasing regional aridity caused by climate change leading to more dust generation (Greve et al., 2017). There is almost 10 years difference in time between this study compared to Gaita et al. (2016), in this time Nairobi has undergone significant increases in population and urbanization with correspondingly higher use of motorization and fuel. Using UN population data (UN, 2014), the population of Nairobi is well modelled by Eq. (1), in which $Y$ is year date, and $p$ is the population in thousands, which suggests that the population of Nairobi has increased by $148 \%$ from 2007 to 2017 .

$p=2.33 \times 10^{-31} \exp \left(3.91 \times 10^{-2} \times Y\right)$

Hence, the population increase alone cannot account for the increase in PM concentration. The pollution production capability per capita could have increased, which is very likely because of the increased rates of motorization and fuel use. If we assume that the increase in PM is solely due to population increase and per capita pollution, it suggests that in 2017 the average citizen is $70 \%$ more polluting than the average citizen in 2007. 
(a)

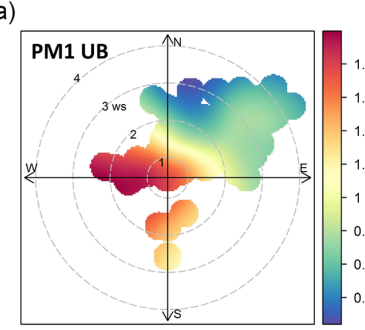

(d)

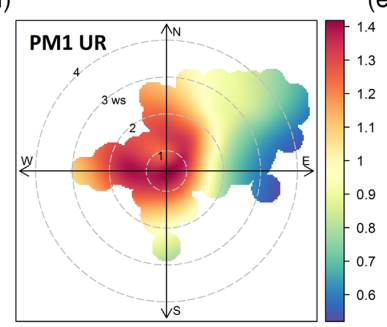

(b)

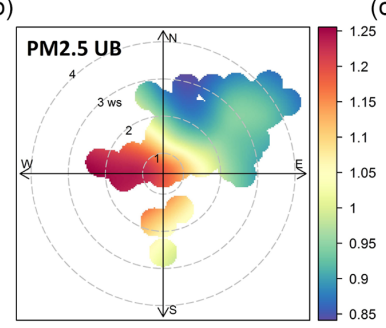

(e)

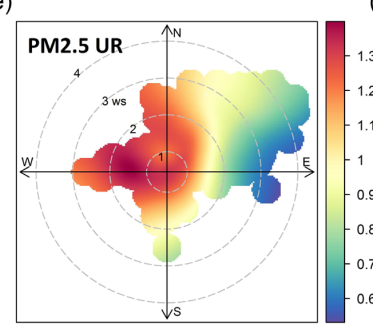

(c)

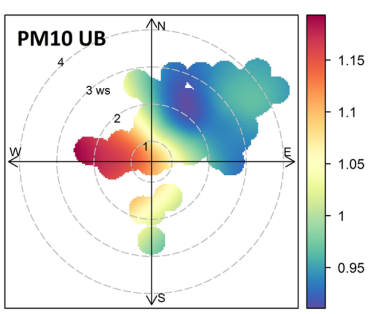

(f)

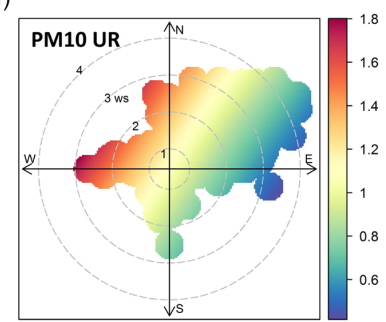

Figure 6. Bivariate (polar) plots of PM in different size fractions at urban background (UB) and urban roadside (UR) sites. Panel descriptions (a) $\mathrm{PM}_{1} \mathrm{UB}$, (b) $\mathrm{PM}_{2.5} \mathrm{UB}$, (c) $\mathrm{PM}_{10} \mathrm{UB}$, (d) $\mathrm{PM}_{1} \mathrm{UR}$, (e) $\mathrm{PM}_{2.5} \mathrm{UB}$ and (f) $\mathrm{PM}_{10} \mathrm{UR}$. The PM mass concentration data in each plot are normalized to allow for easy comparison between the different sites and PM size fractions investigated. However, note the scale bars are different for each panel to allow for easier interpretation.

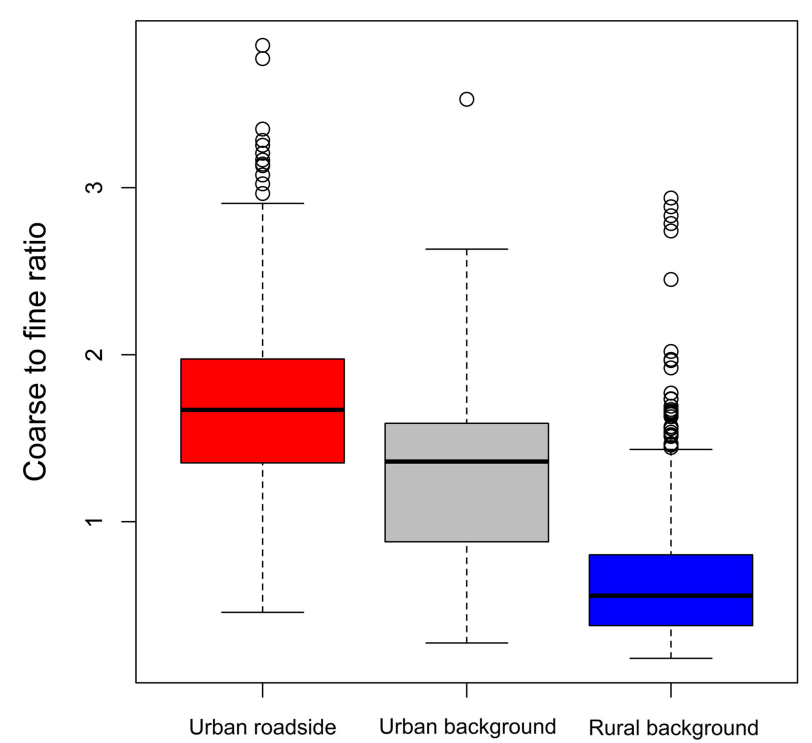

Figure 7. Ratio of the coarse $\left(\mathrm{PM}_{10}-\mathrm{PM}_{2.5}\right)$ to fine $\left(\mathrm{PM}_{2.5}\right)$ fraction of PM.

The Egondi et al. (2016) study of $\mathrm{PM}_{2.5}$ in two slums in Nairobi reported much higher values of 166 and $67 \mu \mathrm{g} \mathrm{m}^{-3}$ for two different slum areas within Nairobi. These values are much higher than the average $\mathrm{PM}_{2.5}$ values from this study; Egondi et al. (2016) stated that the reason for such high levels of $\mathrm{PM}_{2.5}$ stemmed from the local situation and distinct sources of PM within the two slums. This study used a TSI
OPC, which was placed $1.5 \mathrm{~m}$ a.g.l. Therefore, these measurements were likely highly influenced by resuspended dust.

Although Kinney et al. (2011) measured PM$_{2.5}$ levels at four roadside locations, the sampling window was only $11 \mathrm{~h}$ and therefore it is not possible to directly compare this study to it. However, considering the diurnal variation in PM found in this study, both investigations measured similar $\mathrm{PM}_{2.5}$ levels. Kinney et al. (2012) recorded daytime concentration ranges of 10.7 and $98.1 \mu \mathrm{g} \mathrm{m}^{-3}$ for a rural and urban roadside site, respectively, compared to ca. 25 and ca. $150 \mu \mathrm{g} \mathrm{m}^{-3}$ for this study. Again, the increase between sampling years may be a reflection of the increased population, vehicular traffic and rapid urbanization.

\section{Discussion}

In this study, we have shown that Nairobi currently has very high levels of PM mass concentration in the $\mathrm{PM}_{1}, \mathrm{PM}_{2.5}$ and $\mathrm{PM}_{10}$ mass fractions. These measurements were conducted using low-cost calibrated OPC-N2 sensors. The measured $\mathrm{PM}_{2.5}$ and $\mathrm{PM}_{10}$ concentrations at both the urban roadside and urban background sites regularly exceeded the WHO daily limits and very likely exceed the annual limits. In particular, the roadside site often showed concentrations that are double the WHO guidelines. These concentrations will very likely be causing significant harm to the population of Nairobi. 
The negative health effect of PM is linked to the level of exposure experienced by the patient. This paper and others (e.g. Gaita et al., 2014) have shown that in Nairobi, vehicle emissions are the most significant source of PM. Hence, in Nairobi and other similar cities, the exposure to outdoor PM is to a large extent a function of ones proximity to roads. Furthermore, since traffic varies diurnally, seasonally and by day of the week, personal exposure is both spatially and temporally dependent. This spatial and temporal heterogeneity leads to health inequalities in cities. The urban poor who are often most vulnerable to environmental risks due to lack of adequate health provision, typically live in close proximity to roadways, heightening their exposure to vehicular emissions. Stemming from poorly planned rapid urbanization and inadequate service provision within these cities, those that are unable to afford public transport or personal vehicles frequently walk along these pollution heavy roads, only increasing their exposure periods (Hajat et al., 2015).

This study only looked at outdoor air quality, it is important to stress that a significant amount of air pollution deaths in Kenya and SSA in general are due to poor indoor air quality (Mannucci and Franchini, 2017). As a total number of deaths, deaths related to indoor air quality in Kenya rose to $18 \%$ from 1990 to 2013 (Roy, 2016). In LMICs, indoor exposure to pollutants is typically from the household combustion of solid fuels on open fires or traditional stoves (Yip et al., 2017). These exposures increase the risk of acute lower respiratory infections and associated mortality among young children; indoor air pollution from solid fuel use is also a major risk factor for cardiovascular disease, chronic obstructive pulmonary disease and lung cancer among adults (Muindi et al., 2016).

This study has shown that the low-cost OPC-N2 sensors can be used to generate diurnal PM data sets with good precision and repeatability. As noted in the methodology, it would have been preferable for more cross-calibration periods with the tried and tested gravimetric PM measurement, but resources did not allow this. In addition to more calibration points, the study could have been enhanced by the inclusion of collocated calibration points for the roadside and rural background sites in addition to the urban background site, since the average particle shape, size and density will likely be different between the three sites because of differing PM sources and emission factors. However, it is noted that whilst it is desirable from a purely scientific point of view to have more inter-comparison with reference-grade equipment, every inter-comparison adds significant additional cost to the project both in terms of consumables for the gravimetric analysis (including the cost of analytical-grade filters and accompanying laboratory supplies) and the cost of workers. Many other cities in SSA and other LMICs do not have the resource that Nairobi does in having a gravimetric sampler. These additional costs required for highly accurate scientific results would likely make the low-cost sensors not so very low cost after all, and hence bring into question their unique selling point.

Whilst this paper focused on PM pollution, it is noted that there are serious risks to health not only from exposure to PM but also from exposure to ozone $\left(\mathrm{O}_{3}\right)$, nitrogen dioxide $\left(\mathrm{NO}_{2}\right)$ and sulfur dioxide $\left(\mathrm{SO}_{2}\right)$ (Lelieveld et al., 2015). As with PM, concentrations are often highest in the urban areas of LMICs. Ozone is a major factor in asthma morbidity and mortality, while nitrogen dioxide and sulfur dioxide can also play a role in asthma, bronchial symptoms, lung inflammation and reduced lung function. Good quality measurements of these gas phase pollutants lag behind measurements of PM in Nairobi, other SSA cities and LMIC cities in general. This is due to the high importance of PM as an environmental risk factor but also because of the lack of good quality gas analysers which are affordable and transportable.

\section{Conclusions}

Air quality in many LMIC urban centres is often poor and in many cities is getting worse due to the combined pressures of increasing population, increasing urbanization, increasing vehicular traffic and poor vehicle regulation. To be able to manage air pollution, good quality and long-term data sets are required. Unfortunately, in many LMICs the cost of certified high-quality air quality measurements is beyond the financial means of environmental authorities. Low-cost sensors offer the possibility of air quality products at significantly lower cost compared to traditional methods.

This paper used calibrated OPC-N2 devices to measure PM concentrations in Nairobi, Kenya, in the size fractions $\mathrm{PM}_{1}, \mathrm{PM}_{2.5}$ and $\mathrm{PM}_{10}$. The data required calibration using an established gravimetric approach to PM measurement. The need for calibration by trained scientists significantly increases the costs associated with low-cost monitoring and this cost needs to be factored in when assessing options for air quality monitoring.

PM was measured in three locations: an urban roadside, urban background and rural background site for a period of approximately 2 months. The data reveals that roadside and urban background locations in Nairobi often exceed the WHO guidelines for daily averaged PM mass concentration in both the $\mathrm{PM}_{2.5}$ and $\mathrm{PM}_{10}$ size fractions. Comparison of these data with previous measurements conducted in Nairobi is difficult, but where comparison is possible it appears that air quality has become worse in the last 10 years, which is likely due to increases in population, urbanization and motorization. Changes in industry may also influence the air quality. Comparison of the data from the three sites, following a Lenschow-type approach, allowed for the calculation of representative roadside and urban increments for Nairobi (Lenschow et al., 2001). This increment data can be used in future air quality modelling to assess the likely health impact of PM pollution on Nairobi's population. The combination of 
the diurnal PM data with local meteorology allows for simple source apportionment of the PM. The diurnal PM concentration tracks the Nairobi rush hours; furthermore, PM peaks when the wind comes from the direction of significant numbers of vehicles such as major roads and a matatu stop. These facts taken together point towards vehicle emissions being the major sources of air pollution in Nairobi, as has been previously observed in studies such as Gaita et al. (2014). The coarse PM fraction increases at the roadside site compared to the urban background site suggesting that non-exhaust vehicle emissions make up a significant amount of the vehicle emissions.

In summary, the low-cost sensors used in this study provided many useful data for assessing air quality in Nairobi at an equipment cost significantly lower than that of traditional instruments. Low-cost sensors have great potential in other country settings and could be used for long-term sampling if the appropriate calibrations are performed.

Data availability. Original research data are available from the authors upon request.

\section{The Supplement related to this article is available online at: https://doi.org/10.5194/acp-18-15403-2018- supplement}

Author contributions. FDP and MG devised the study. The data analysis was carried out by DN and RB with guidance from FDP and MG. AP designed the air pollution monitoring boxes. FDP and $\mathrm{RB}$ led the manuscript writing with input from all authors.

Competing interests. The authors declare that they have no conflict of interest.

Acknowledgements. Leigh Crilley and Robin Price are thanked for their help in optimizing the OPC-N2 monitoring systems. This work was funded via an EPSRC grant (Global Challenges Research Fund IS2016), the Royal Society and Royal Society of Chemistry International Exchanges Award (IE170267), and DFID via the East African Research Fund (EARF) grant "A Systems Approach to Air Pollution (ASAP) East Africa”. Scientific research support by International Science Programme in Sweden to the Institute of Nuclear Science \& Technology in the University of Nairobi was appreciated.

Edited by: Delphine Farmer

Reviewed by: three anonymous referees

\section{References}

Beddows, D. C., Dall'Osto, M., and Harrison, R. M.: Cluster analysis of rural, urban, and curbside atmospheric particle size data, Environ. Sci. Technol., 43, 4694-4700, 2009.

Brauer, M., Amann, M., Burnett, R. T., Cohen, A., Dentener, F., Ezzati, M., Henderson, S. B., Krzyzanowski, M., Martin, R. V., Van Dingenen, R., van Donkelaar, A., and Thurston, G. D.: Exposure Assessment for Estimation of the Global Burden of Disease Attributable to Outdoor Air Pollution, Environ. Sci. Technol., 46, 652-660, https://doi.org/10.1021/es2025752, 2012.

Carslaw, D. C. and Beevers, S. D.: Characterising and understanding emission sources using bivariate polar plots and k-means clustering, Environ. Modell. Softw., 40, 325-329, 2013.

Carslaw, D. C. and Ropkins, K.: Openair - An R package for air quality data analysis, Environ. Modell. Softw., 27-28, 52-61, https://doi.org/10.1016/j.envsoft.2011.09.008, 2012.

Chen, R., Hu, B., Liu, Y., Xu, J., Yang, G., Xu, D., and Chen, C.: Beyond $\mathrm{PM}_{2.5}$ : The role of ultrafine particles on adverse health effects of air pollution, BBA-Gen. Subjects, 1860, 2844-2855, https://doi.org/10.1016/j.bbagen.2016.03.019, 2016.

Crilley, L. R., Shaw, M., Pound, R., Kramer, L. J., Price, R., Young, S., Lewis, A. C., and Pope, F. D.: Evaluation of a low-cost optical particle counter (Alphasense OPC-N2) for ambient air monitoring, Atmos. Meas. Tech., 11, 709-720, https://doi.org/10.5194/amt-11-709-2018, 2018.

deSouza, P., Nthusi, V., Klopp, J. M., K., Shaw, B. E., Ho, W. O., Saffell, J., Jones, R., and Ratti, C.: A Nairobi experiment in using low cost air quality monitors, Clean Air, 27, 12-42, 2017.

Egondi, T., Muindi, K., Kyobutungi, C., Gatari, M., and Rocklov, J.: Measuring exposure levels of inhalable airborne particles $\left(\mathrm{PM}_{2.5}\right)$ in two socially deprived areas of Nairobi, Kenya, Environ. Res., 148, 500-506, https://doi.org/10.1016/j.envres.2016.03.018, 2016.

Fan, Z., Meng, Q., Weisel, C., Shalat, S., Laumbach, R., OhmanStrickland, P., Black, K., Rodriguez, M., and Bonanno, L.: Acute short-term exposures to $\mathrm{PM}_{2.5}$ generated by vehicular emissions and cardiopulmonary effects in older adults, Epidemiology, 17, 213-214, https://doi.org/10.1097/00001648200611001-00544, 2006.

Ferranti, E. J. S., MacKenzie, A. R., Ashworth, K., and Hewitt, C. N.: First Steps in Urban Air Quality, A Trees and Design Action Group, 2017.

Gaita, S. M., Boman, J., Gatari, M. J., Pettersson, J. B. C., and Janhäll, S.: Source apportionment and seasonal variation of $\mathrm{PM}_{2.5}$ in a Sub-Saharan African city: Nairobi, Kenya, Atmos. Chem. Phys., 14, 9977-9991, https://doi.org/10.5194/acp-149977-2014, 2014.

Gaita, S. M., Boman, J., Gatari, M. J., Wagner, A., and Jonsson, S. K.: Characterization of Size-Fractionated Particulate Matter and Deposition Fractions in Human Respiratory System in a Typical African City: Nairobi, Kenya, Aerosol Air Qual. Res., 16, 23782385, https://doi.org/10.4209/aaqr.2016.01.0019, 2016.

Gatari, M., Boman, J., and Maina, D.: Trace element categorization of pollution sources in the equator town of Nanyuki, Kenya, X-Ray Spectrom., 34, 118-123, https://doi.org/10.1002/xrs.771, 2005.

Greve, P., Roderick, M. L., and Seneviratne, S. I.: Simulated changes in aridity from the last glacial maximum to $4 x \mathrm{CO}_{2}$, 
Environ. Res. Lett., 12, p114021, https://doi.org/10.1088/17489326/aa89a3, 2017.

Gulis, G., Mulumba, J. A. A., Juma, O., and Kakosova, B.: Health status of people of slums in Nairobi, Kenya, Environ. Res., 96, 219-227, https://doi.org/10.1016/j.envres.2004.01.016, 2004.

Hagan, D.: py-opc, available at: https://github.com/dhhagan/py-opc (last access: 2 February 2018), 2017.

Hajat, A., Hsia, C., and O'Neill, M. S.: Socioeconomic disparities and air pollution exposure: a global review, Curr. Environ. Health Rep., 2, 440-450, 2015.

Hays, M. D., Cho, S. H., Baldauf, R., Schauer, J. J., and Shaferd, M.: Particle size distributions of metal and non-metal elements in an urban near-highway environment, Atmos. Environ., 45, 925-934, https://doi.org/10.1016/j.atmosenv.2010.11.010, 2011.

HEI Panel on the Health Effects of Traffic-Related Air Pollution: Traffic-Related Air Pollution: A Critical Review of the Literature on Emissions, Exposure, and Health Effects, HEI Special Report 17, 2010.

Kam, W., Liacos, J. W., Schauer, J. J., Delfino, R. J., and Sioutas, C.: Size-segregated composition of particulate matter (PM) in major roadways and surface streets, Atmos. Environ., 55, 90-97, https://doi.org/10.1016/j.atmosenv.2012.03.028, 2012.

Kenya Population: http://worldpopulationreview.com/countries/ kenya-population/, last access: 19 April 2018.

Kinney, P. L., Gichuru, M. G., Volavka-Close, N., Ngo, N., Ndiba, P. K., Law, A., Gachanja, A., Gaita, S. M., Chillrud, S. N., and Sclar, E.: Traffic Impacts on $\mathrm{PM}_{2.5}$ Air Quality in Nairobi, Kenya, Environ. Sci. Policy, 14, 369-378, https://doi.org/10.1016/j.envsci.2011.02.005, 2011.

Kenya National Bureau of Statistics :http://www.knbs.or.ke/index. php?option=com_phocadownload\&view=category\&id=106: statistical-19 (last access: 18 October 2018), 2015.

Landrigan, P. J., Fuller, R., Acosta, N. J. R., Adeyi, O., Arnold, R., Basu, N. N., Balde, A. B., Bertollini, R., Bose-O'Reilly, S., Boufford, J. I., Breysse, P. N., Chiles, T., Mahidol, C., CollSeck, A. M., Cropper, M. L., Fobil, J., Fuster, V., Greenstone, M., Haines, A., Hanrahan, D., Hunter, D., Khare, M., Krupnick, A., Lanphear, B., Lohani, B., Martin, K., Mathiasen, K. V., McTeer, M. A., Murray, C. J. L., Ndahimananjara, J. D., Perera, F., Potocnik, J., Preker, A. S., Ramesh, J., Rockstrom, J., Salinas, C., Samson, L. D., Sandilya, K., Sly, P. D., Smith, K. R., Steiner, A., Stewart, R. B., Suk, W. A., van Schayck, O. C. P., Yadama, G. N., Yumkella, K., and Zhong, M.: The Lancet Commission on pollution and health, Lancet, 391, 462512, https://doi.org/10.1016/S0140-6736(17)32345-0, 2017.

Lelieveld, J., Evans, J. S., Fnais, M., Giannadaki, D., and Pozzer, A.: The contribution of outdoor air pollution sources to premature mortality on a global scale, Nature, 525, 367, 2015.

Lenschow, P., Abraham, H. J., Kutzner, K., Lutz, M., Preuss, J. D., and Reichenbacher, W.: Some ideas about the sources of $\mathrm{PM}_{10}$, Atmos. Environ., 35, 23-33, 2001.

Lewis, A. and Edwards, P.: Validate personal air-pollution sensors, Nature, 535, 29-31, https://doi.org/10.1038/535029a, 2016.

Lewis, A. C., Lee, J. D., Edwards, P. M., Shaw, M. D., Evans, M. J., Moller, S. J., Smith, K. R., Buckley, J. W., Ellis, M., Gillot, S. R., and White, A.: Evaluating the performance of low cost chemical sensors for air pollution research, Faraday Discuss., 189, 85-103, https://doi.org/10.1039/c5fd00201j, 2016.
Mannucci, P. M. and Franchini, M.: Health effects of ambient air pollution in developing countries, Int. J. Env. Res. Pub. He., 14, 1048, 2017.

Meng, X., Ma, Y. J., Chen, R. J., Zhou, Z. J., Chen, B. H., and Kan, H. D.: Size-Fractionated Particle Number Concentrations and Daily Mortality in a Chinese City, Environ. Health Persp. 121, 1174-1178, https://doi.org/10.1289/ehp.1206398, 2013.

Mitlin, D. and Satterhwaite, D.: Urban poverty in the global south: scale and nature, Routledge, London, 2013.

Muindi, K., Kimani-Murage, E., Egondi, T., Rocklov, J., and Ng, N.: Household Air Pollution: Sources and Exposure Levels to Fine Particulate Matter in Nairobi Slums, Toxics, 4, 12, https://doi.org/10.3390/toxics4030012, 2016.

Ngo, N. S., Gatari, M., Yan, B. Z., Chillrud, S. N., Bouhamam, K., and Kinney, P. L.: Occupational exposure to roadway emissions and inside informal settlements in sub-Saharan Africa: A pilot study in Nairobi, Kenya, Atmos. Environ., 111, 179-184, https://doi.org/10.1016/j.atmosenv.2015.04.008, 2015.

Ochieng, C., Khaemba, W., Mwaniki, R., and Kimotho, S.: Climate and Environmental Justice in Africa, African Centre for Technology Studies, Nairobi, Kenya, 2017.

Pant, P. and Harrison, R. M.: Estimation of the contribution of road traffic emissions to particulate matter concentrations from field measurements: A review, Atmos. Environ., 77, 78-97, https://doi.org/10.1016/j.atmosenv.2013.04.028, 2013.

Pateraki, S., Asimakopoulos, D. N., Bougiatioti, A., Maggos, T., Vasilakos, C., and Mihalopoulos, N.: Assessment of $\mathrm{PM}_{2.5}$ and $\mathrm{PM}_{1}$ chemical profile in a multiple-impacted Mediterranean urban area: origin, sources and meteorological dependence, Sci. Total Environ., 479-480, 210-220, https://doi.org/10.1016/j.scitotenv.2014.02.008, 2014.

Petkova, E. P., Jack, D. W., Volavka-Close, N. H., and Kinney, P. L.: Particulate matter pollution in African cities, Air Qual. Atmos. Hlth, 6, 603-614, https://doi.org/10.1007/s11869-0130199-6, 2013.

Petters, M. D. and Kreidenweis, S. M.: A single parameter representation of hygroscopic growth and cloud condensation nucleus activity - Part 2: Including solubility, Atmos. Chem. Phys., 8, 6273-6279, https://doi.org/10.5194/acp-8-6273-2008, 2008.

Pringle, K. J., Tost, H., Pozzer, A., Pöschl, U., and Lelieveld, J.: Global distribution of the effective aerosol hygroscopicity parameter for CCN activation, Atmos. Chem. Phys., 10, 52415255, https://doi.org/10.5194/acp-10-5241-2010, 2010.

Rai, A. C., Kumar, P., Pilla, F., Skouloudis, A. N., Di Sabatino, S., Ratti, C., Yasar, A., and Rickerby, D.: End-user perspective of low-cost sensors for outdoor air pollution monitoring, Sci. Total Environ., 607, 691-705, https://doi.org/10.1016/j.scitotenv.2017.06.266, 2017.

Rajé, F., Tight, M., and Pope, F. D.: Traffic pollution: a search for solutions for a city like Nairobi, Journal of Cases on Information Technology, In press, https://doi.org/10.1016/j.cities.2018.05.008, 2017.

Roy, R.: The cost of air pollution in Africa, https://doi.org/10.1787/18151949, 2016.

Seinfield, J. J. and Sypyros, P. N.: Atmospheric chemistry and physics: from air pollution to climate change, John Willey \& Sons, New York, 2016.

Thorpe, A. J., Harrison, R. M., Boulter, P. G., and McCrae, I. S.: Estimation of particle resuspension source strength on 
a major London Road, Atmos. Environ., 41, 8007-8020, https://doi.org/10.1016/j.atmosenv.2007.07.006, 2007.

Thurston, G. D., Ahn, J., Cromar, K. R., Shao, Y. Z., Reynolds, H. R., Jerrett, M., Lim, C. C., Shanley, R., Park, Y., and Hayes, R. B.: Ambient Particulate Matter Air Pollution Exposure and Mortality in the NIH-AARP Diet and Health Cohort, Environ. Health Perspect., 124, 484-490, https://doi.org/10.1289/ehp.1509676, 2016.

Trippetta, S., Sabia, S., and Caggiano, R.: Fine aerosol particles $\left(\mathrm{PM}_{1}\right)$ : natural and anthropogenic contributions and health risk assessment, Air Qual. Atmos. Hlth, 9, 621-629, https://doi.org/10.1007/s11869-015-0373-0, 2016.

Tsiouri, V., Kakosimos, K. E., and Kumar, P.: Concentrations, sources and exposure risks associated with particulate matter in the Middle East Area - a review, Air Qual. Atmos. Hlth, 8, 6780, https://doi.org/10.1007/s11869-014-0277-4, 2015. van Vliet, E. D. S. and Kinney, P. L.: Impacts of roadway emissions on urban particulate matter concentrations in sub-Saharan Africa: new evidence from Nairobi, Kenya, Environ. Res. Lett., 2, 045028, https://doi.org/10.1088/1748-9326/2/4/045028, 2007.

Wan Mahiyuddin, W. R., Sahani, M., Aripin, R., Latif, M. T., Thach, T.-Q., and Wong, C.-M.: Short-term effects of daily air pollution on mortality, Atmos. Environ., 65, 69-79, https://doi.org/10.1016/j.atmosenv.2012.10.019, 2013.

World Health Organization: WHO Air quality guidelines for particulate matter, ozone, nitrogen dioxide and sulfur dioxide-Global update 2005-Summary of risk assessment, 2006, Geneva: WHO, 2006.

Yip, F., Christensen, B., Sircar, K., Naeher, L., Bruce, N., Pennise, D., Lozier, M., Pilishvili, T., Farrar, J. L., and Stanistreet, D.: Assessment of traditional and improved stove use on household air pollution and personal exposures in rural western Kenya, Environ. Int., 99, 185-191, 2017. 